\title{
Results in the Use of Two Types of Polymeric Appliances in the Therapy of Some Mild Sleep Apnea Simptoms
}

\author{
EDWIN SEVER BECHIR ${ }^{1}$, ANAMARIA BECHIR ${ }^{2}$, OANA CRISTINA ARGHIR ${ }^{3 *}$, GABRIELA CIAVOI ${ }^{4}$, CHERANA GIOGA², \\ FARAH CURT MOLA ${ }^{1}$, IONELA TEODORA DASCALU ${ }^{5}$ \\ ${ }^{1}$ University of Medicine and Pharmacy Tirgu Mures, Faculty of Dental Medicine, 38 Gheorghe Marinescu Str., 540139 Tirgu \\ Mures, Romania \\ ${ }^{2}$ Titu Maiorescu University of Bucharest, Faculty of Dental Medicine, 67A Gh. Petrascu Str., 031593, Bucharest, Romania \\ ${ }^{3}$ University Ovidius of Constanta, Faculty of Medicine, 1 Al. Universitatii, 900470 Constanta, Romania \\ ${ }^{4}$ University of Oradea, Faculty of Medicine and Pharmacy, 1 Decembrie Sq, 3700 Oradea, Romania \\ ${ }^{5}$ University of Medicine and Pharmacy Craiova, Faculty of Dental Medicine, 2 Petru Rares Str., 200349, Craiova, Romania
}

\begin{abstract}
Sleep apnea episodes represent a problem both for the patients and for the patient's bed partners. The objective of this study was to record the comparative effects of two types of polymeric appliances in the therapy of some mild apnea symptoms (bruxism and snoring). The effectof therapy with the used appliances was pursued on 42 patients, divided in two groups. In the first group of 21 patients, we used a custom made appliance achieved by Erkoflex disks, and in the second group of 21 patients, the preformed SomnoFit 8 Oscimed polymeric appliance. The survey lasted for a 12 month period, 1 month before the insertion in mouth of the appliances and 11 months therapy with polymeric appliances. The authors' questionnaire was completed daily by the patients and their bed partners, which noted the night comfort with inserted appliances in the mouth, the existence/absence of morning pain in the area of the masseter muscle, existence/absence of the morning fatigue, respectively the maintaining, diminishing and the absence of snoring and of nocturnal bruxism. The results of the study were favorable and proved that the nocturnal therapy of bruxism and of snoring, by using these two polymeric appliances were efficient. SomnoFit ${ }^{\circledR}$ appliance performed better in reducing bruxism and snoring, but custom made Erkoflex appliances presented a greater resistance in time.
\end{abstract}

Keywords: Sleep apnea, bruxism, snoring, polymeric dental appliances

Sleep is a reversible behavioral state of perpetual disengagement from and unresponsiveness to the environment $[1,2]$. Sleep disorders involve any difficulties related to sleeping, including snoring, sleep apnea, insomnia, sleep deprivation, and restless legs syndrome. Obstructive sleep apnea (OSA) is characterized by repetitive episodes of complete (apnea) or partial (hypopnea), and the upper airway obstruction is occurred during sleep [3]. OSA is an extremely common public health problem manifested by sleep-disordered breathing, daytime hypersomnia and poor sleep quality, adverse neurocognitive sequelae, hypoxia a.s. [4]. Symptoms may be present for years, even decades without identification, during which time the sufferer may become conditioned to the daytime sleepiness and fatigue, associated with significant levels of sleep disturbance [5]. The effects of sleep disorders on the patient's health are numerous, including arterial hypertension, coronary heart disease, stroke, etc. [6-8].

Sleep apnea is recognized as a problem both for the patients because by its effects/sequelaes on patient body and for the witnesses of patient during sleep apnea episodes [9]. Snoring is a respiratory sound generated in the upper airway during sleep that typically occurs during inspiration but may also occur in expiration $[10,11]$. OSA occurs in about two to four percent of the general population, or an estimated 18 million Americans [12].

During sleep, the muscular tone of the throat is relaxed and the tongue presents a backward movement, which reduce the size of the air passage. That causes turbulence and vibration in the flexible region of the palate and the pharynx, which causes the sound in snoring. Apart from the audible nuisance that disturbs the others, snoring can develop into a more severe obstruction of the air passage, characterised by pauses in breathing of variable duration. This more severe pathology, called sleep apnea, justifies a medical consultation and treatment [13].

In the figure 1 are presented the normal and collapsed superior airways (specific in OSA).
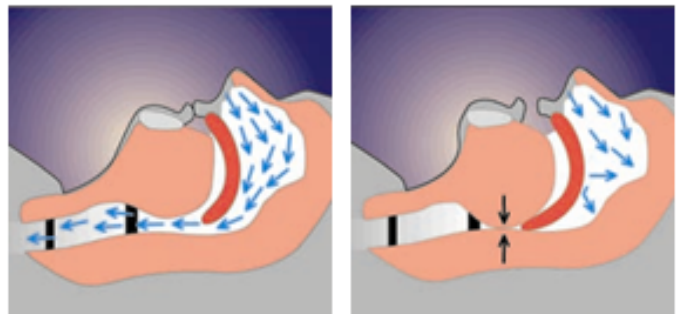

Fig. 1. Schematic aspects of normal (left) and collapsed (right) superior airways

Snoring is a condition that can be controlled [14]. Because snoring is usually more of a complaint for the bed partner than it is for the snorer, the noise is typically the primary reason for seeking a medical consult [15]. $45 \%$ of normal adults snore at least occasionally and $25 \%$ are habitual snorers. Problem snoring is more frequent in males and overweight people and usually worsens with age. Snoring may be an indication of obstructed breathing and should not be taken lightly [16]. Sleep bruxism consists of forceful, involuntary, parafunctional grinding and/or clenching of teeth, during the waking state and/or sleep and can damage the various components of the masticatory system [17]. Teeth grinding or clenching may be loud enough to awaken the sleep partner $[18,19]$. The cause of bruxism is not completely agreed upon, but daily stress may be the trigger in many people $[20,21]$. The 
dysfunctional syndrome of oro-facial system represents an interference disease between multiple specialties, and for a correct diagnosis need a completely conjunction between specialty of dentistry and some medical specialties like specialists in sleep diseases, in otorhinolaryngology, neurology, endocrinology, psychiatry, a.s. $[22,23]$.

Dental resins are commonly used in dentistry for different purposes, including anti-snoring or bruxism dental appliances, due to their advantages as good physical properties, sufficient strength, low water sorption, low solubility [24]. A large number of studies were published regarding the materials for different dental appliances, but it has not been possible to reach a consensus about the product that represents the gold standards [25]. The indications for thermoplastic polymers include flexible dentures, preformed clasps, flexible partial denture framework, temporary or provisional crowns and bridges, orthodontic appliances, anti-snoring devices, different types of mouthguards and splints [26,27]. Thermoplastic polymers have been used for dental appliances fabrication for decades. Even though it has a few favorable characteristics (the ability to form at low temperatures and cost), there are not considered a very shock-absorbent material $[28,29]$.

Erkoflex (Erkodent - Erich Kopp $\mathrm{GmbH}$ ) is a soft-elastic material used for achievement thermoformed dental appliances. Erkoflex discs used in our study, have deep red colour rubbery discs, with $2 \mathrm{~mm}$ thickness, and with a hardness shore of $A: 82$. The plasticization of this material were realised by thermoforming, in special units, as Erkoform-3 (fig. 2) [30].

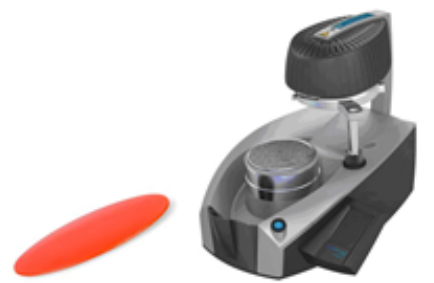

Fig. 2. Aspect of an Erkodent disc and of Erkoform-3

thermoforming device

Erkoflex discs composition are represented by ethylvinylacetate (EVA) copolymer, a copolymer of ethylene with vinylacetate (va:app. 28\%), with $\left(\mathrm{C}_{2} \mathrm{H}_{4}\right)_{0}\left(\mathrm{C}_{4} \mathrm{H}_{6} \mathrm{O}_{2}\right)_{m}$ chemical formula [31,32]. For achievement the custom made Erkoflex thermoformed appliances, were necessary the impression of dental arches, the pouring of the models of hard plaster and thermoforming of Erkofles-95 discs on models (best working Erkoflex disks is at app. $130^{\circ} \mathrm{C}$ temperature, in the Erkoform-3 thermoforming unit). Heating is effectuated until foil sags, but the heating time depends on foil thickness and heating device. The custom made appliance is permanently elastic [33,34].

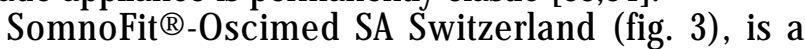
preformed and individually adjusted mandibular advancement appliance, made of two oral mouldings in
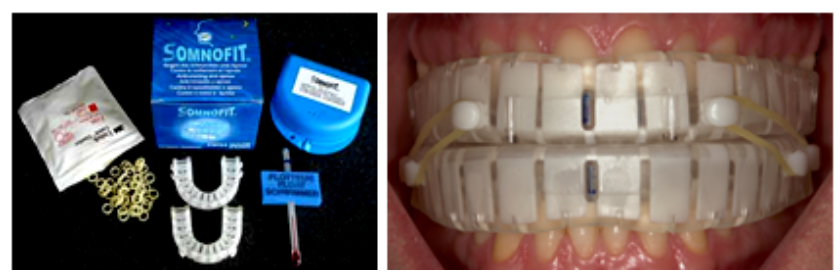

Fig. 3. Aspect of Somnofit@-Oscimed preformed appliance fitting shell trays that are fitted to the upper and lower jaw. Each moulding is made from highly pliable thermoformable material, which adapts to any dental morphology and ensures comfortable retention in the mouth. There are simply immersed in heated water to soften the thermal moulding material and fitted to the teeth of dental arches. The two mouldings are then joined by a supple strap, which guides the lower jaw advancement, adjustable from 3.0 to $10.5 \mathrm{~mm}$, on 6 positions. During sleep, the appliance hold the lower jaw forward by a few millimetres and this advancement clears space around the back of the tongue to allow inhaled air to flow freely $[35,36]$.

The objective of the study was to research the possibilities in diminishing night bruxism and snoring in a batch of 42 patients, by using thermoformed interocclusal appliances, custom made by Erkoflex Discs and preformed Somnofit $\circledast$ appliance.

\section{Experimental part}

\section{Materials and methods}

The effect of treatment with inter-occlusal mandibular advancement appliances was pursued on 42 patients, by using tw 0 type of polymeric advancement appliances, one custom made appliance realized by Erkoflex disks ( 21 patients), and one represented by SomnoFit $₫$ preformed polymeric appliance (21 patients).

From the initially of 53 interdisciplinary investigated patients (between October 2014 and March 2015), the monitoring and the evaluation of the 42 selected patients, was performed during April 2015-March 2016. Our clinical experimental study was carried out on 42 patients, ages between 19-53 years old, with a recommendation for applying interocclusal thermoformed appliances after an interdisciplinary diagnosis of mild sleep apnea, manifested by snoring and bruxism. The survey lasted for a 12 month period, 1 month before the insertion in mouth and 11 months therapy.

The distribution of patients after gender and after the type of treatment is presented in table 1 .

We designed a questionnaire with contained answers of the patients (in relation with the presence/absence of nocturnal comfort in sleeping with the occlusal devices inserted in mouth, the presence/absence of morning pain in masseter muscle, the presence/absence of the morning fatigue), and the patient's bed partners (the presencel absence of nocturnal bruxism, the presence/absence of snoring, in the period of using the appliances). The questionnaire was completed daily by patients and by the patient's bed partners and the answers were recorded as follows:

$1=$ patient statement regarding the presence of nocturnal comfort with dental appliance;

2 = patient statement regarding the absence of nocturnal comfort with dental appliance;

$3=$ patientstatement regarding the presence of morning pain in masseter muscle;

4 = patient statementregarding the absence of morning pain in masseter muscle;

$5=$ patientstatement regarding the presence of morning fatigue;

$6=$ patient statement regarding the absence of morning fatigue;

\begin{tabular}{|c|c|c|c|c|c|c|c|c|c|}
\hline \multicolumn{2}{|c|}{$\begin{array}{l}\text { Total number } \\
\text { of patients (42) }\end{array}$} & \multicolumn{2}{|c|}{$\begin{array}{l}\text { Patients with } \\
\text { bruxism (42) }\end{array}$} & \multicolumn{2}{|c|}{$\begin{array}{l}\text { Patients with } \\
\text { snoring (42) }\end{array}$} & \multicolumn{2}{|c|}{$\begin{array}{l}\text { Patients with } \\
\text { Erkoflex (2l) }\end{array}$} & \multicolumn{2}{|c|}{$\begin{array}{l}\text { Patients with } \\
\text { Somnofit (2l) }\end{array}$} \\
\hline Male & Female & Male & Female & Male & Female & Male & Female & Male & Female \\
\hline$\overline{23}$ & 19 & 23 & 19 & $\overline{23}$ & $\overline{19}$ & $\overline{12}$ & 9 & 11 & 10 \\
\hline
\end{tabular}

MATERIALE PLASTICE $\diamond 54$ No. 2 • 2017
Table 1

THE DISTRIBUTION OF PATIENTS AFTER GENDER AND AFTER THE TYPE OF TREATMENT 
7 = patient's bed partners statement regarding the presence of bruxism;

$8=$ patient's bed partners statement regarding the absence of bruxism;

9 ps = patient's bed partners statement regarding the presence of snoring;

$10=$ patient's bed partners statement regarding the absence of snoring.

\section{Results and discussions}

We performed a monthly summarization of the recorded data's by patients and by patient's bed partners. The statements during the twelve months of researches are presented in table 2 .

The results of the study were favorable and proved that the nocturnal therapy of bruxism and of snoring, by using both polymeric appliances was efficient. Especially in the first few weeks of treatment with these appliances, the patients needed to be more frequently encouraged.

SomnoFit ${ }^{\circledR}$ appliance performed better in all statements (nocturnal comfort, morning pain in masseter muscle, morning fatigue, bruxism and snoring) in comparison with Erkoflex appliance, probably due to the mandibular advancement possibility of this appliance. Due the material elasticity, Erkoflex appliances showed a good mechanical strength during the research, but after 10 months of use, the thickness in the occlusal area decreased to $1.5 \mathrm{~mm}$.

The patient's compliance is a very important key factor in the therapy with dental appliances [37].

After the statements of producer, SomnoFit ${ }^{\circledR}$ is recommended for snoring, mild to moderate obstructive sleep apnea, sleep apnea patients on the move, travelling, camping, boating, holidaying, who prefer an alternative to their usual CPAP therapy, bruxism, migraines due to jaw tensions, but medical supervision is required $[38,39]$. SomnoFit $\circledast$ mandibular advancement medical device is efficient against snoring in more than $90 \%$ of cases. The average rate of loss in relation to obstructive sleep apnea is about $60 \%$, but it depends on each individual case, and therefore requires individual control [40-42]. SomnoFit $\AA$ cautions are in relation with the patients under 18 years old, patients who wear removable dentures, patients with loosed teeth or advanced periodontal disease, and patients who have mandibular joint pain [43].

The deformation and the fracture of the appliances determined by the excessive occlusal forces, by parafunctional habits or by bruxism, represent one of the most frequent problems of interocclusal devices [44]. The achievements of dental appliances by vacuum thermoforming technology representan alternative to the classical heat cured technique, which improve their clinical performances [45].

As a simpler alternative to CPAP, oral appliances are often regarded by patients as a more acceptable treatment option for OSA. Future research should focus on determining the influence of the design of oral appliances on clinical outcome, the development of a clinically reliable method for identifying those patients who are mostlikely to achieve a favorable treatment response, and the characterization of factors predisposing to long-term adverse effects of oral appliance treatment [46,47].

In the review of the Health Quality Ontario [48], were analyzed the clinical effectiveness of mandibular advancement appliances (MAA), compared to treatment with continuous positive airway pressure (CPAP) of OSA. The results of review revealed that there were no clear patient's preferences among the studies. Polysomnography represent the gold standard for the assessment of suspected sleep disorders and offer analysis of polygraphic physiologic variables as electroencephalography (EEG) electrocardiogram (ECG) and chin and limb electromyography (EMG). EMG analyze periodic leg movements, oro-nasal airflow, and the respiratory effort [49].

The medical comorbidities of obstructive sleep apnea are presented in figure 4.

Fig. 4. Obstructive sleep apnea and its medical comorbidities

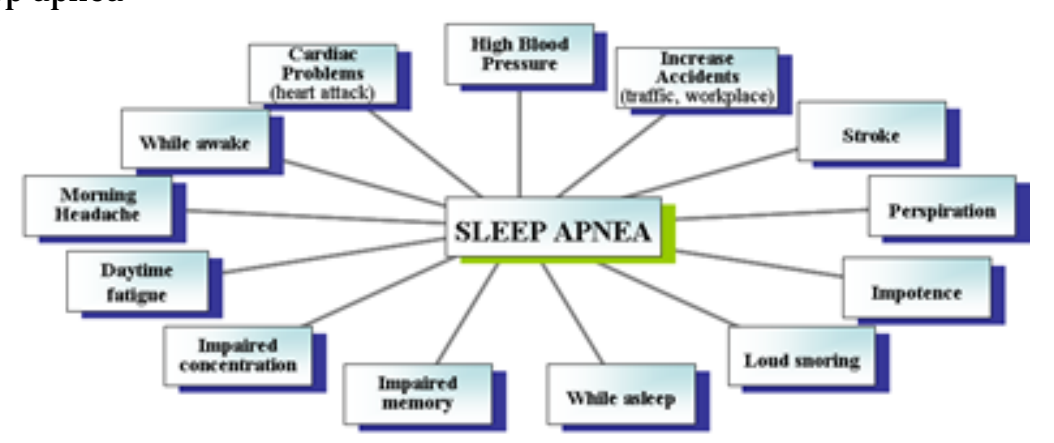

Table 2

MONTLY SUMARISATION OF THE PATIENTS AND THE PATIENT'S BED PARTNERS STATEMENTS

\begin{tabular}{|c|c|c|c|c|c|c|c|c|c|c|c|c|c|c|c|c|c|c|c|c|}
\hline \multirow{3}{*}{ Month } & \multicolumn{20}{|c|}{ Statement } \\
\hline & \multicolumn{2}{|c|}{1} & \multicolumn{2}{|c|}{2} & \multicolumn{2}{|c|}{3} & \multicolumn{2}{|c|}{4} & \multicolumn{2}{|c|}{5} & \multicolumn{2}{|c|}{6} & \multicolumn{2}{|c|}{7} & \multicolumn{2}{|c|}{8} & \multicolumn{2}{|c|}{9} & \multicolumn{2}{|c|}{10} \\
\hline & $\mathrm{E}$ & $\mathrm{S}$ & $\mathrm{E}$ & $\mathbf{S}$ & $\mathrm{E}$ & $\mathrm{S}$ & $\mathrm{E}$ & $\mathrm{S}$ & $\mathrm{E}$ & $\mathbf{S}$ & $\mathrm{E}$ & $\mathrm{S}$ & $E$ & $\mathrm{~S}$ & $E$ & $\mathbf{S}$ & $\mathrm{E}$ & $\mathrm{S}$ & $E$ & $\mathrm{~S}$ \\
\hline 1 & $\overline{-}$ & - & - & - & 21 & 21 & - & - & 21 & 21 & - & - & 21 & 21 & - & - & 21 & 21 & - & - \\
\hline 2 & 17 & 16 & 4 & 5 & 18 & 18 & 3 & 3 & 5 & 6 & 16 & 15 & 17 & 15 & 4 & 6 & 16 & 14 & 5 & 7 \\
\hline 3 & 20 & 19 & 1 & 2 & 19 & 19 & 2 & 2 & 4 & 4 & 17 & 17 & 14 & 12 & 7 & 9 & 12 & 11 & 9 & 10 \\
\hline 4 & 21 & 21 & 0 & 0 & 20 & 21 & 1 & 0 & 3 & 2 & 18 & 19 & 12 & 8 & 9 & 13 & 10 & 6 & 11 & 15 \\
\hline 5 & 21 & 21 & 0 & 0 & 21 & 21 & 0 & 0 & 1 & 0 & 20 & 21 & 8 & 6 & 13 & 15 & 7 & 4 & 14 & 17 \\
\hline 6 & 21 & 21 & 0 & 0 & 21 & 21 & 0 & 0 & 0 & 0 & 21 & 21 & 5 & 3 & 16 & 18 & 3 & 1 & 18 & 20 \\
\hline 7 & 21 & 21 & 0 & 0 & 21 & 21 & 0 & 0 & 0 & 0 & 21 & 21 & 2 & 0 & 19 & 21 & 1 & 0 & 21 & 21 \\
\hline 8 & 21 & 21 & 0 & 0 & 21 & 21 & 0 & 0 & 0 & 0 & 21 & 21 & 0 & 0 & 21 & 21 & 0 & 0 & 21 & 21 \\
\hline 9 & 21 & 21 & 0 & 0 & 21 & 21 & 0 & 0 & 0 & 0 & 21 & 21 & 0 & 0 & 21 & 21 & 0 & 0 & 21 & 21 \\
\hline 10 & 21 & 21 & 0 & 0 & 21 & 21 & 0 & 0 & 0 & 0 & 21 & 21 & 0 & 0 & 21 & 21 & 0 & 0 & 21 & 21 \\
\hline 11 & 21 & 21 & 0 & 0 & 21 & 21 & 0 & 0 & 0 & 0 & 21 & 21 & 0 & 0 & 21 & 21 & 0 & 0 & 21 & 21 \\
\hline 12 & 21 & 21 & 0 & 0 & 21 & 21 & 0 & 0 & 0 & 0 & 21 & 21 & 0 & 0 & 21 & 21 & 0 & 0 & 21 & 21 \\
\hline
\end{tabular}


The research of Checherita et al [50] shows that the therapy with soft-occlusal appliances has better long-term results in reducing the symptoms of dysfunctional syndrome and improves the patients' status.

\section{Conclusions}

The therapy of bruxism and of snoring, through SomnoFit and Erkoflex thermoformed appliances was effective and had positive results.

The use of anti-bruxism and anti-snoring appliances can be with an equal benefit for patient and to one's sleeping partner (by treating one allowing two, to sleep better!).

Treating these sleep disorders appears both dental and medical benefits.

Prospective randomized controlled trials are needed to test the assumption that these treatment modalities are effective in time.

\section{References}

1.KRYGER M.H., ROTH T., AND DEMENT W.C.: Normal human sleep: an overview. In: Kryger M.H., Roth T., and Dement W.C., eds. Principles and Practice of Sleep Medicine. 4th ed. Philadelphia: Elsevier/Saunders. 2005; p. 13-24

2.LEE-CHIONG T.L.: Sleep: A Comprehensive Handbook. 1st ed. Hoboken, New Jersey: Wiley-Liss/J ohnWiley \& Sons. 2006; p. 19-53 3.STOOHS RA, KNAACK L, BLUM H, et al, Sleep Med. 2008, 9, p. 121134

4.YOUNG T, PALTA M, DEMPSEY J, SKATRUD J, WEBER S, BADR S. N Engl J Med. 1993, 328, p. 1230

5.*** http://emedicine.medscape.com/article/295807-overview

6.ARBOIX A. World Journal of Clinical Cases/ : WJCC. 2015; 3 (5), p. 418

7.*** http://www.goodnightmedical.com/sleep-problems/healthaffects-of-sleep-disorders.html

8.PARTINEN M., PUTKONEN PTS., KAPRIO J, KOSKENVUO M, HILAKIVI I. Acta Medica Scandinavica, 1982, 211, 69, 83

9.RANDERATH WJ, SANNER BM, SOMERS VK. Sleep Apnea. Prog Respir Res. Basel, Karger, 2006, vol 35, p. 118

10.*** https://sleepfoundation.org/sleep-disorders-problems/othersleep-disorders/snoring

11.*** http://www.webmd.com/sleep-disorders/guide/snoring

12.St LOUIS EK. Pract Neurol (Fort Wash Pa). 2010; 9, 4, p. 26

13.*** www.somnofit.com

14.***http://www. britishsnoring.co.uk/

15.***http://www.webmd.com/sleep-disorders/guide/sleep-disordersdiagnosis-tests

16.***http://www.entnet.org/content/snoring-and-sleep-apnea

17.***http://ww w.mayoclinic.org/diseases-conditions/bruxism/basics/ definition/con-20029395

18.**https://sleep.ai/information/grinding-bruxism/

19. VAHEDIFAR M, Bruxism, Lulu Publisher Co, 2015 ed., p. 24-26

20.*** https://sleepfoundation.org/sleep-disorders-problems/bruxismand-sleep

21.LOBBEZOO F, van der ZAAG J, van SELMS MK, HAMBURGER HL, NAEIJE M. J ournal of Oral Rehabilitation, 2008, 35, 7, p. 509
22.MITRO V., CASCINO F, REALE G., RINNA C, FILIACI F., Eur. Rev. Med. Pharmacol. Sci., 2012, 16, 13, p. 1878

23.CHECHERITA ,L.E, FORNA, N.C, STAMATIN, O, COBZARU, R, LEON, MM, CIOLOCA, D, Rev. Chim. (Bucharest), 64, no. 10, 2013, p. 1172 24.DIACONU, POPA D., VITALARIU, A., TATARCIUC, M., MUNTEANU, F., Rev. Chim.(Bucharest) , 67, no. 8, 2016, p. 1571

25.BECHIR, A., BECHIR, E.S., MANU, R., BURCEA, A., GIOGA, C., BARBU, H.M., BIRIS, C., CIAVOI, G., DASCALU, I.T, Mat. Plast, 53, no. 4, 2016, p. 661

26. ARDELEAN, L, BORTUN, C, PODARIU, AC, RUSU, LC, Mat. Plast., 49, no. 1, 2012, p. 30

27.ARDELEAN, L, BORTUN, C, MOTOC, M, RUSU, LC, Mat. Plast., 47, no. 41,2010, p. 433

28.GOULD TE, PILAND SG, SHIN J, HOYLE CE, NAZARENKO S., Dent Mater., 2009, Vol. 25, No. 6, p. 771

29.GOULD TE, PILAND SG, SHIN J, MCNAIR O, HOYLE CE, NAZARENKO S., Dent Mater. 2009, Vol. 25, No. 12, p. 1593

30.*** http://www.erkodent.com/dental/html_english/geraete.html

31.***http://w w w.erkodent.com/dental/html_francais/ produkt.php?recordID $=10259$

32.*** https://en.wikipedia.org/wiki/Ethylene-vinyl_acetate

33.*** www.erkodent.com

34.*** erkodent.de/dental/anleit/OcclBruxMichStab.pdf

35.*** http://www.medisleep.de/pages/patient/somnofit_eng.html

36.***http://www.oscimedsa.com/anti_snoring_apnoea_ somnofit device

37.SZUHĀNEK, C, JIANU, R, SCHILLER, E, BUDURU, S, POPA, A, BUZATU, R, PETRESCU, HP, GRIGORE, A, Mat. Plast., 53, no. 4,2016, p. 675

38.**http://www.snoringcure.ca/oscimed_SomnoFit $®$ _mandibular_ advancement_device.htm

39.*** http://www.snoringcure.ca/somnolis_and_SomnoFit ${ }^{\circ}$ comparison_mandibular_advancement_medical_devices_that treat_stop_snoring_obstructive_sleep_apnea_and_prevent_grinding_ of teeth.htm

40.*** http://www.snoringcure.ca/pdf/SomnoFit@/SomnoFit@_EN1.pdf 41.BECHIR A, GHERGIC DL, BECHIR ES, Romanian Journal of Stomatology, 2007, Vol. LIII, No. 4, Ed. Med. Amaltea, p. 200

42.*** http://www.SomnoFit $\circledast$.co.uk/clinical-evidence.mad 43.*** http://www.oscimedsa.com/anti_snoring_apnoea_SomnoFit $\circledast$ device

44.JIVANESCU, $A_{1}$, HRELESCU MIHUTESCU,D,,GOGUTA, L, PIRVULESCU, L,D, Mat. Plast., 53, no. 3, 2016, p. 481

45.BECHIR, A., PACURAR, M., BECHIR, E.S., COMANEANU, M.R., CHIBELEAN, CIRES, M., MARIS, M., BARBU, HM, Mat. Plast., 51, no. 1, 2014, p. 57

46.*** www.sleepfoundation.org

47.*** www.asaa.org

48.Medical Advisory Secretariat. Oral appliances for obstructive sleep apnea: an evidence-based analysis. Ontario Health Technology Assessment Series 2009; 9, 5:1-51

49.St LOUIS EK. Pract Neurol (Fort Wash Pa). 2010 Sep; 9 , 5:26

50.CHECHERITA,L., BELDIMAN, M,A, STAMATIN, O., FOIA, L., FORNA, N,C., Rev. Chim.(Bucharest), 64, no.8, 2013, p.866

Manuscript received: 2.05 .2017 